\title{
Population structure in the spider mite Tetranychus urticae (Acari: Tetranychidae) from Crete based on multiple allozymes
}

\author{
ANASTASIA TSAGKARAKOU* $\uparrow$, MARIA NAVAJAS $\uparrow$, JACQUES LAGNEL $+\& ~ N I C O L E$ \\ PASTEUR \\ Institut des Sciences de l'Evolution (CNRS, URA 327), Laboratoire Génétique et Environnement, Université de \\ Montpellier II (case courrier 065), Place E. Bataillon, 34095 Montpellier and †Laboratoire de Zoologie, INRA, 2, Place \\ P. Viala, 34060 Montpellier, France
}

\begin{abstract}
The polymorphism of four isozymes was studied on single females of Tetranychus urticae from Crete (Greece), using an isoelectric focusing technique. Genetic differentiation was found to be correlated with distance but not with the species of colonized host-plants. Thus no differentiation was observed between samples collected on citrus trees, tomato, pumpkin, okra or weed plants located within a $50 \mathrm{~m}^{2}$ area, showing that at this geographical scale $T$. urticae populations are panmictic. In contrast, samples from plants at $150 \mathrm{~m}$ or more from one another displayed a significant genetic differentiation. These results are discussed in relation to the known pattern of migration in the species.
\end{abstract}

Keywords: allozymes, gene flow, host-plant adaptation, population structure.

\section{Introduction}

The phytophagous two-spotted spider mite, Tetranychus urticae Koch, is distributed worldwide. It feeds on a large variety of plant families including many crops, and displays a large amount of variation in its morphology, physiology (tolerance to insecticides, response to photoperiod), sex ratios, etc. (Helle \& Overmeer, 1973). Reproductive incompatibilities, possibly caused by endosymbionts (Tsagkarakou et al., 1996a), have often been recorded (de Boer, 1985). Few studies attempting to clarify the genetic differentiation associated with this variation have been undertaken. This is mainly because of the difficulty of using classical electrophoresis techniques to analyse the genetic polymorphism of these very small organisms. Until recently, only a single enzymatic system could be studied on each individual (Ward et al., 1982; Gotoh et al., 1993; Hinomoto \& Takafuji, 1994). In 1991, Kazmer described an isoelectrofocusing (IEF) method which uses several stacked cellulose acetate membranes and allowed the investigation of up to five enzymatic systems on single Trichogramma. This technique has since been used successfully to evaluate citrus thrips

\footnotetext{
*Correspondence. E-mail: tsagka@ensam.inra.fr
}

predation by the phytoseiid mite Euseius tularensis Congdon (Jones \& Morse, 1995) and by us to analyse the genetic variability of a few collections of T. urticae from Greece (Tsagkarakou et al., 1996b). This last investigation revealed a high level of polymorphism and prompted us to investigate the genetic differentiation of this species in the Mediterranean region. The present study was undertaken to answer two questions: (a) is there any genetic differentiation caused by selection pressures relative to the host plant colonized, and (b) how does geographical distance influence the gene flow between $T$. urticae populations? To answer these questions we tried to find $T$. urticae populations inhabiting as many as possible different host plant species within a small area, as well as populations separated by distances of different orders of magnitude. For this purpose, the island of Crete (Greece) where familial vegetable gardens with several plant species can be found near citrus groves appeared well suited.

\section{Material and methods}

Mite samples

Twelve samples of mites were collected in September 1995 at Neo Chorio and Armeni (Crete), two 
villages about $50 \mathrm{~km}$ from one another (Fig. 1). In each village, samples of 30-40 females and males were collected from different host-plant species. If densities were high ( $>30$ mites) individual plants or leaves were sampled independently (Table 1). All samples collected in Neo Chorio came from a $50 \mathrm{~m}^{2}$ area whereas samples collected in Armeni came from two sites of about $30 \mathrm{~m}^{2}$ separated by $150 \mathrm{~m}$. Males were used to determine the species present in each sample by microscopic examination. Only $T$. urticae was found. Females were stored in liquid nitrogen until electrophoresis.

\section{Electrophoresis}

Single females were homogenized directly on the top of four stacked cellulose acetate membranes and submitted to isoelectric focusing as described by Tsagkarakou et al. (1996b). After migration, each membrane was used to reveal 6-phosphogluconate dehydrogenase (PGD, EC 1.1.1.44), phosphoglucomutase (PGM, EC 5.4.2.2), esterases (EST, EC 3.1.1.-) or phosphoglucoisomerase (PGI, EC 5.3.1.9), as described by Pasteur et al. (1988). These enzyme systems were the only ones among the 13 with activity to show polymorphism and to have clear genotypes (Tsagkarakou et al., 1996b).

\section{Population structure}

Population structure was analysed with the GENEPOP (version 2) software (Raymond \& Rousset, 1995a). $F_{1 \mathrm{~S}}$ and $F_{\mathrm{ST}}$ estimates were computed according to Weir \& Cockerham (1984). Heterozygote deficits or excesses were tested using an exact test procedure (Rousset \& Raymond, 1995). When a null allele was present (Est-3 locus), the maximum likelihood estimates of allelic frequencies under Hardy-Weinberg equilibrium were computed using the algorithm of Dempster et al. (1977). Genotypic associations between each pair of loci were tested for each popu-

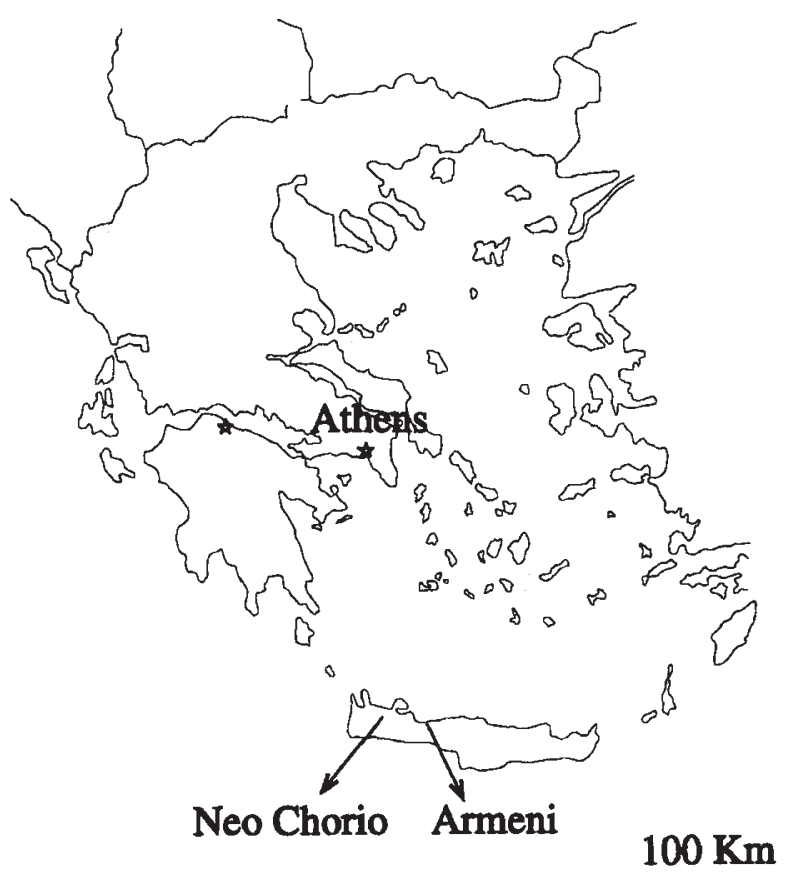

Fig. 1 Geographical location of the two villages in Crete where samples of Tetranychus urticae were collected. The samples nos 123-130 were collected at Neo Chorio, within an area of $50 \mathrm{~m}^{2}$. At Armeni, samples nos 131 and 132 were separated by $150 \mathrm{~m}$ from samples nos 133 and 134. Details about the nature of sampling are given in Table 1. Stars indicate the location of the continental samples described in Tsagkarakou et al. (1996b).

Table 1 Collection records of Tetranychus urticae sampled in Crete (Greece) in September 1995

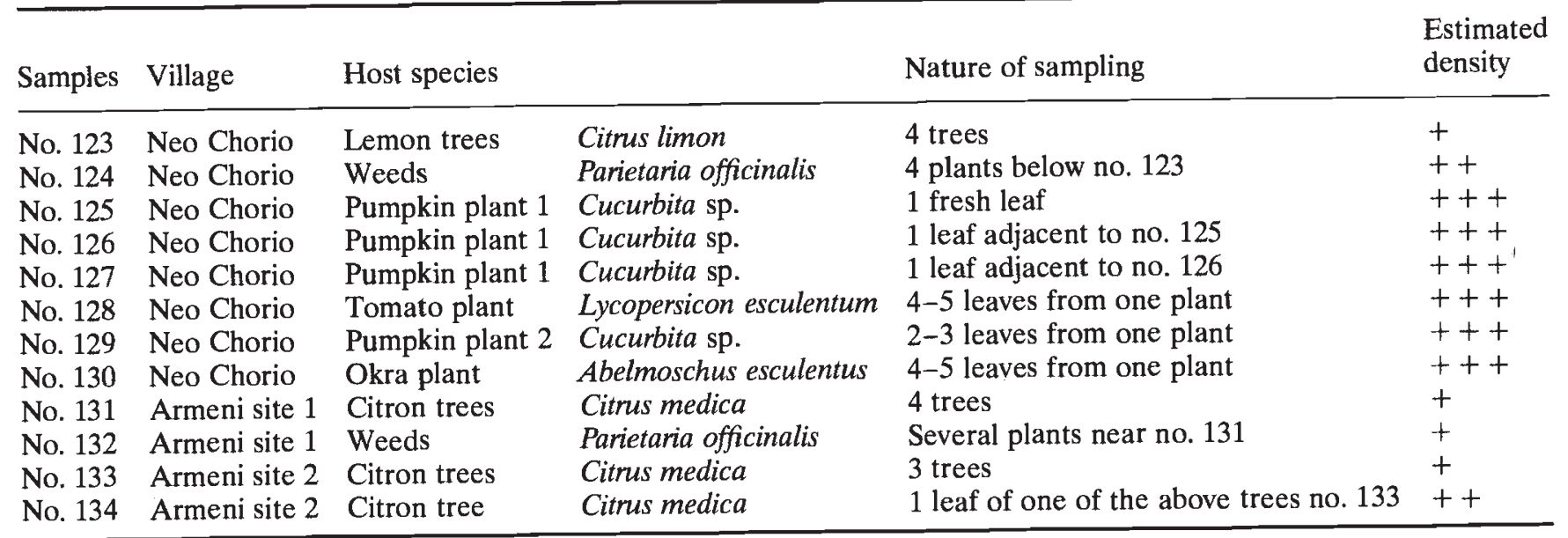


lation by a probability test as described by Raymond \& Rousset (1995b), and over the whole data set by Ohta's variance analysis (Ohta, 1982) using the LINKDOs program (Garnier-Gere \& Dillmann, 1992). When necessary, the significance level of each test was adjusted by taking into account the other tests using the sequential Bonferroni method (Holm, 1979).

Genotypic differentiation between populations or groups of populations was tested by computing an unbiased estimate of the $P$-value of an $F_{\mathrm{ST}}$-based exact test (Raymond \& Rousset, 1995a) as implemented in GENEPOP. The overall significance of multiple tests was estimated by Fisher's combined probability test (Fisher, 1970). The number of effective migrants $(\mathrm{Nm})$ was computed from $F_{\mathrm{ST}}$ estimates according to the equation $N m=\left(1 / F_{\mathrm{ST}}-1\right) / 4$ (Wright, 1969) or by using the private allele method of Slatkin (1985). Isolation by distance was tested statistically by determining the significance of the correlation between $F_{\text {ST }}$ estimates and geographical distances using a Mantel test where $P$-values are determined by permutation procedures (Smouse $e t$ al., 1986; Leduc et al., 1992).

\section{Results}

\section{Genetic polymorphism}

The four enzymatic systems investigated allowed the identification of six putative loci. Three of these loci (Pgd, Pgm, and Pgi) displayed allozyme patterns which were consistent with the presence of codominant alleles (Table 2). The three other loci encoded esterases which hydrolysed preferentially either alpha (Est-1 locus) or beta (Est-2 and Est-3 loci) naphthyl acetate. Est-1 allozymes presented a weak and inconstant staining and are not considered further. Three alleles were found for Est-2 and all mites displayed one (homozygotes) or two (heterozygotes) allozymes. Three alleles were also observed at the Est-3 locus but, in all samples except no. 132, some individuals lacked Est-3 activity. To determine whether the absence of Est-3 activity resulted from the presence of a null allele or from another factor, deviations from Hardy-Weinberg expectations were analysed in considering first only mites with Est-3 activity, and then all mites. The first analysis disclosed heterozygote deficits $(P<0.05)$ in samples nos 123, 124, 125, 128 and 133, an observation consistent with the possible presence of a null allele. The second analysis was performed after estimating allelic frequencies of active and null alleles (Table
2), by maximum likelihood assuming the HardyWeinberg equilibrium. If lack of activity resulted from a null allele and if the populations were in Hardy-Weinberg equilibrium, the expected and the observed phenotype frequencies should have coincided. This was not the case in six (nos 124, 125, $126,127,129,130)$ of the 10 polymorphic samples in which significant deviations from Hardy-Weinberg expectations $\left(15<\chi_{6}^{2}<38, \quad 0.02>P>10^{-5}\right)$ were obtained. This result suggests that either one or both hypotheses are wrong and the Est-3 locus is not considered further.

The analysis of the genotypic distributions at the Est-2, Pgd, Pgi and Pgm loci (Table 2) disclosed significant heterozygote deficits $(P<0.05)$ in five out of 26 tests: two at the Pgd locus (nos 131 and 132) and three at the Pgm locus (nos 123, 126 and 133). All these deficits except that of no. 126 remained significant $(P<0.05)$ when taking into account multiple tests (sequential Bonferroni tests). Samples nos 123, 131, 132 and 133 were collected from several plants (each plant carrying a low density of mites), and the observed heterozygote deficits may be an indication of a Wahlund effect. Pooling samples nos 126, 127, 128, 129 and 130 collected in Neo Chorio on individual plants or leaves (with high densities of mites) did not lead to a heterozygote deficit or to an increase of $F_{\text {IS }}$ estimates $\left(F_{\text {IS }}=-0.005,-0.019\right.$ and -0.146 for Pgm, Est-2 and Pgi, respectively) as compared to those obtained with individual samples (see Table 2). These results seem to suggest that density is an important parameter in the population structure of $T$. urticae.

The analysis of genotypic associations between pairs of loci in each sample revealed a single nonrandom association (between Pgm and Est-2 in no. 126) which did not remain significant $(P>0.05)$ when taking into account multiple tests. The linkage disequilibrium between two alleles of a pair of loci within a subdivided population is caused either by directional selection pressures or to genetic drift. To discriminate between the two situations, we followed the procedure of Ohta (1982) which decomposes the gametic associations observed in the whole data set $\left(D_{\mathrm{IT}}\right)$ into four indices to discriminate the part created within ( $D_{\mathrm{IS}}$ and $D_{\text {IS }}^{\prime}$ ), from that created between $\left(D_{\mathrm{ST}}\right.$ and $\left.D^{\prime}{ }_{\mathrm{ST}}\right)$, populations. For all pairs of loci, $D_{\mathrm{IS}}<D_{\mathrm{ST}}$ and $D^{\prime}{ }_{\text {IS }}>D_{\text {ST }}^{\prime}$ (Table 3 ), indicating that genetic drift rather than selection is responsible for the nonrandom genotypic associations found among the T. urticae populations studied here. These analyses indicated that the variability observed at the different loci was not redundant, and that it could be used to analyse gene flow. 
Table 2 Allelic frequencies and inbreeding coefficient $\left(F_{\text {IS }}\right)$ in samples of Tetranychus urticae

\begin{tabular}{|c|c|c|c|c|c|c|c|c|c|c|c|c|}
\hline \multirow[b]{2}{*}{ Locus } & \multicolumn{12}{|c|}{ Samples } \\
\hline & 123 & 124 & 125 & 126 & 127 & 128 & 129 & 130 & 131 & 132 & 133 & 134 \\
\hline \multicolumn{13}{|l|}{$P g d$} \\
\hline$N$ & 35 & 32 & 31 & 15 & 25 & 11 & 30 & 24 & 32 & 41 & 33 & 30 \\
\hline 100 & 1.000 & 1.000 & 1.000 & 1.000 & 1.000 & 1.000 & 1.000 & 1.000 & 0.938 & 0.951 & 1.000 & 0.950 \\
\hline 90 & 0.000 & 0.000 & 0.000 & 0.000 & 0.000 & 0.000 & 0.000 & 0.000 & 0.063 & 0.049 & 0.000 & 0.050 \\
\hline$F_{\text {IS }}$ & - & - & - & - & - & - & - & - & $1^{* * *}$ & $1^{* * *}$ & - & -0.04 \\
\hline \multicolumn{13}{|l|}{ Pgm } \\
\hline$N$ & 27 & 30 & 31 & 30 & 42 & 30 & 26 & 28 & 30 & 39 & 33 & 30 \\
\hline 100 & 0.389 & 0.567 & 1.000 & 0.633 & 0.548 & 0.400 & 0.462 & 0.536 & 0.650 & 0.590 & 0.848 & 0.817 \\
\hline 80 & 0.611 & 0.433 & 0.000 & 0.350 & 0.452 & 0.600 & 0.538 & 0.464 & 0.183 & 0.333 & 0.000 & 0.017 \\
\hline 120 & 0.000 & 0.000 & 0.000 & 0.017 & 0.000 & 0.000 & 0.000 & 0.000 & 0.167 & 0.077 & 0.152 & 0.167 \\
\hline$F_{\mathrm{IS}}$ & $0.62^{* *}$ & 0.07 & - & $0.38^{*}$ & 0.05 & 0.05 & -0.22 & $-0.42^{*}$ & 0.17 & 0.34 & $0.77^{* * *}$ & -0.19 \\
\hline \multicolumn{13}{|l|}{ Est-2 } \\
\hline$N$ & 35 & 32 & 31 & 32 & 42 & 27 & 30 & 29 & 33 & 39 & 32 & 30 \\
\hline 100 & 1.000 & 0.984 & 0.952 & 0.984 & 1.000 & 1.000 & 0.950 & 0.948 & 0.955 & 0.987 & 1.000 & 1.000 \\
\hline 110 & 0.000 & 0.000 & 0.048 & 0.000 & 0.000 & 0.000 & 0.000 & 0.000 & 0.045 & 0.013 & 0.000 & 0.000 \\
\hline 115 & 0.000 & 0.016 & 0.000 & 0.016 & 0.000 & 0.000 & 0.050 & 0.052 & 0.000 & 0.000 & 0.000 & 0.000 \\
\hline$F_{\text {IS }}$ & - & - & -0.03 & - & - & - & -0.04 & -0.04 & 0.03 & - & - & - \\
\hline \multicolumn{13}{|l|}{$P g i$} \\
\hline$N$ & 35 & 32 & 31 & 15 & 25 & NA & 30 & 29 & 33 & 41 & 33 & 30 \\
\hline 100 & 0.871 & 0.797 & 0.968 & 0.900 & 0.900 & & 0.867 & 0.828 & 0.985 & 0.902 & 1.000 & 1.000 \\
\hline 90 & 0.129 & 0.203 & 0.032 & 0.100 & 0.100 & & 0.133 & 0.172 & 0.015 & 0.098 & 0.000 & 0.000 \\
\hline$F_{\text {IS }}$ & -0.13 & -0.24 & -0.02 & -0.08 & -0.09 & & -0.14 & -0.19 & - & -0.10 & - & - \\
\hline \multicolumn{13}{|l|}{ Est -3} \\
\hline$N$ & 25 & 32 & 31 & 25 & 32 & 24 & 25 & 26 & 28 & 12 & 19 & NA \\
\hline 70 & 0.267 & 0.218 & 0.305 & 0.307 & 0.345 & 0.410 & 0.320 & 0.420 & 0.407 & 0.542 & 0.388 & \\
\hline 80 & 0.377 & 0.383 & 0.262 & 0.145 & 0.247 & 0.150 & 0.261 & 0.153 & 0.095 & 0.083 & 0.091 & \\
\hline 90 & 0.040 & 0.062 & 0.193 & 0.280 & 0.250 & 0.145 & 0.260 & 0.269 & 0.270 & 0.375 & 0.272 & \\
\hline Null & 0.314 & 0.335 & 0.238 & 0.266 & 0.157 & 0.293 & 0.158 & 0.157 & 0.226 & 0.000 & 0.247 & \\
\hline
\end{tabular}

Samples numbered as in Table 1.

The Est-3 frequencies were estimated by maximum likelihood except for sample 132 (see text).

$N$, number of tested individuals; NA, not available.

Significant heterozygote deficits or excess: ${ }^{*} P<0.05,{ }^{*} P<0.01$ and ${ }^{* * *} P<0.001$.

\section{Genetic differentiation and gene flow}

Genetic differentiation was analysed by comparing genotypic distributions and computing $F_{\mathrm{ST}}$ estimates. It was highly significant $\left(P<10^{-5}\right)$ over all samples $\left(F_{\mathrm{ST}}=0.12\right)$ as well as among samples from each village $\left(F_{\mathrm{ST}}=0.093\right.$ and 0.065 for Neo Chorio and Armeni, respectively, Table 4). To understand better the forces responsible for this differentiation within each village, all pairs of samples were compared.

For Neo Chorio, where all samples were collected within a $50 \mathrm{~m}^{2}$ area on different plant species, significant differences were restricted to comparisons including sample no. $125 \quad\left(P<10^{-5} ; 0.24<\right.$ $\left.F_{\mathrm{ST}}<0.55\right)$. The fact that the overall differentiation observed in Neo Chorio resulted from this sample was confirmed by removing it from the analysis: differentiation was no longer significant $(P=0.07$ and $\left.F_{\mathrm{ST}}=0.01\right)$. This indicates that there was no differentiation associated with the host plant species. Samples nos 125, 126 and 127 come from three successive leaves of the same pumpkin branch, the leaf carrying no. 125 being the youngest and thus the most recently colonized. The most likely explanation for no. 125 being differentiated from all the other samples collected in Neo Chorio is a recent founder effect. This conclusion is in agreement with (a) the monomorphism of the Pgm locus which was highly polymorphic in other samples, (b) the presence of allele Est-2 ${ }^{110}$ which was absent from sample nos 126 
Table 3 Variance components of linkage disequilibrium analysis for Tetranychus urticae (Ohta, 1982)

\begin{tabular}{|c|c|c|c|c|c|}
\hline \multirow{2}{*}{ Loci compared } & \multicolumn{2}{|c|}{$\begin{array}{l}\text { Within-subpopulation } \\
\text { components }\end{array}$} & \multicolumn{2}{|c|}{$\begin{array}{l}\text { Between-subpopulation } \\
\text { components }\end{array}$} & \multirow{2}{*}{$\begin{array}{l}\text { Total } \\
D_{\text {IT }}\end{array}$} \\
\hline & $D_{\mathrm{IS}}$ & $D_{\text {IS }}^{\prime}$ & $D_{\mathrm{ST}}$ & $D_{\mathrm{ST}}^{\prime}$ & \\
\hline$P g d-P g m$ & 0.00080 & 0.34846 & 0.08365 & 0.00025 & 0.34871 \\
\hline Pgd-Est-2 & 0.00001 & 0.00860 & 0.00218 & 0.00000 & 0.00860 \\
\hline$P g d-P g i$ & 0.00005 & 0.03626 & 0.01072 & 0.00003 & 0.03629 \\
\hline Pgm-Est-2 & 0.00052 & 0.30809 & 0.08155 & 0.00014 & 0.30823 \\
\hline Pgm-Pgi & 0.00308 & 0.31894 & 0.08130 & 0.00413 & 0.32307 \\
\hline Est-2-Pgi & 0.00003 & 0.04074 & 0.00974 & 0.00001 & 0.04075 \\
\hline
\end{tabular}

Table $4 F_{\mathrm{ST}}$ estimates and number of migrants $(\mathrm{Nm})$ for population subdivisions of Tetranychus urticae

\begin{tabular}{|c|c|c|c|c|c|c|c|c|}
\hline & \multirow[b]{2}{*}{$N \S$} & \multicolumn{5}{|c|}{$F_{\mathrm{ST}}^{\dagger}$} & \multicolumn{2}{|r|}{$N m \neq$} \\
\hline & & 6-Pgd & $P g m$ & Est-2 & $P g i$ & All I & $F_{\mathrm{ST}}$ & Private allele \\
\hline $\begin{array}{l}\text { All samples } \\
\text { Within villages }\end{array}$ & 12 & 0.012 & $0.16^{* * *}$ & $0.016^{* *}$ & $0.049^{* * *}$ & $0.12^{* * *}$ & 1.8 & - \\
\hline Neo Chorio - all samples & 8 & 0 & $0.14 * * *$ & $0.016^{*}$ & 0.015 & $0.093^{* * *}$ & 2.5 & 3.7 \\
\hline - excluding no. 125 & 7 & 0 & 0.016 & 0.014 & -0.002 & 0.01 & 24 & 12 \\
\hline Armeni — all samples & 4 & -0.007 & $0.082 * * *$ & 0.016 & $0.063^{* * *}$ & $0.065^{* * *}$ & 3.6 & - \\
\hline site 1 & 2 & -0.027 & 0.013 & 0.006 & $0.046^{*}$ & 0.012 & 21 & - \\
\hline site 2 & 2 & 0.038 & -0.018 & 0 & 0 & -0.01 & $>24$ & 3.4 \\
\hline \multicolumn{9}{|l|}{ Between sites } \\
\hline Neo Chorio-Armeni & 2 & 0.045 & 0.11 & 0.002 & 0.051 & 0.088 & 2.5 & 1 \\
\hline Armeni: site 1-site 2 & 2 & -0.0004 & $0.12^{* * *}$ & 0.019 & $0.049^{* *}$ & $0.09^{* * *}$ & 2.5 & 1.2 \\
\hline
\end{tabular}

$\dagger$ Estimated by the theta parameter of Weir \& Cockerham (1984).

$\ddagger$ Estimated using both Wright's $F_{\mathrm{ST}}$ and Slatkin's private allele methods.

$\S$ Number of samples considered.

If'All' refers to the multilocus estimate.

Significant genotypic differentiation: ${ }^{*} P<0.05,{ }^{* *} P<0.01$ and ${ }^{* * *} P<0.001$. Probabilities could not be computed for the

Neo Chorio-Armeni comparison because the Armeni group contained differentiated samples.

and 127 from the same pumpkin branch and (c) the low average observed heterozygosity $\left(H_{0}=0.04\right)$ as compared to other samples $\left(H_{\mathrm{o}}=0.11-0.29\right)$ at Neo Chorio.

The Armeni samples were collected from two distinct sites $150 \mathrm{~m}$ from each other. Within each site, genetic differentiation was not significant $\left(P>0.05 ; F_{\mathrm{ST}}=0.012\right.$ and -0.01 for site 1 and site 2). This observation was expected for site 2 because no. 134 was collected on one leaf of the trees carrying no. 133; in the following analyses, these two samples have been pooled. Genetic differentiation $\left(F_{\mathrm{ST}}=0.09\right)$ was significant $\left(P<10^{-5}\right)$ between the two sites of Armeni: both samples (no. 131 collected on citrus and no. 132 collected on weeds) in site 1 differed significantly from sample $(133+134)$ at site
$2\left(P=0.009\right.$ and $F_{\mathrm{ST}}=0.057$ for no. 131 , and $P<10^{-5}$ and $F_{\mathrm{ST}}=0.14$ for no. 132). These results contrast with those obtained for Neo Chorio, and show that $T$. urticae populations separated by $150 \mathrm{~m}$ are not panmictic, whereas populations within an area of $50 \mathrm{~m}^{2}$ are panmictic.

The genetic differentiation between Neo Chorio and Armeni was examined by pooling the samples collected in each village. The $F_{\mathrm{ST}}$ estimate was 0.088 , a value close to that observed between the two sites in Armeni.

Gene flow (Table 4), estimated from the number of effective migrants, $\mathrm{Nm}$, computed from $F_{\mathrm{ST}}$ estimates (or the private allele method which gave comparable results), was high $(N m \geq 21)$ among mites colonizing different plants within an area of 
$50 \mathrm{~m}^{2}$ or less in Armeni or Neo Chorio (sample no. 125 was excluded from this analysis, see above). In contrast, $N m=2.5$ between sites separated by $150 \mathrm{~m}$ in Armeni or between the two villages, indicating that gene flow is strongly reduced by even a short distance $(150 \mathrm{~m})$. The relationship between gene flow and distance was further analysed by examining the slope of the regression between $\log \mathrm{Nm}$ and $\log$ distance computed for each pair of samples (Slatkin, 1993) (Fig. 2), and by computing the correlation between $F_{\mathrm{ST}}$ estimates and distance. The slope of log $N m$ and $\log$ distance was negative $(b=-0.243)$, and $F_{\mathrm{ST}}$ was significantly and positively correlated to geographical distance $(\rho=0.55$; Mantel test: $P=0.02$ ), indicating that gene flow significantly decreases (or genetic differentiation significantly increases) as distance between populations increases.

\section{Genetic differentiation between Crete and Greece}

Comparison of the genetic polymorphism of samples collected in Crete and those collected in continental Greece (Tsagkarakou et al., 1996b) disclosed large differences. First, the Est-3 locus observed in all the samples from Crete was fixed for the null allele or absent from mites of the continent. Secondly, the Est-2 locus possessed seven alleles on the continent vs. three in Crete. Thirdly, allele $P^{2 i 11}{ }^{110}$ present on the continent was absent from Crete, whereas allele $\mathrm{Pgi}^{90}$ present in Crete was absent on the continent. The genetic differentiation between samples

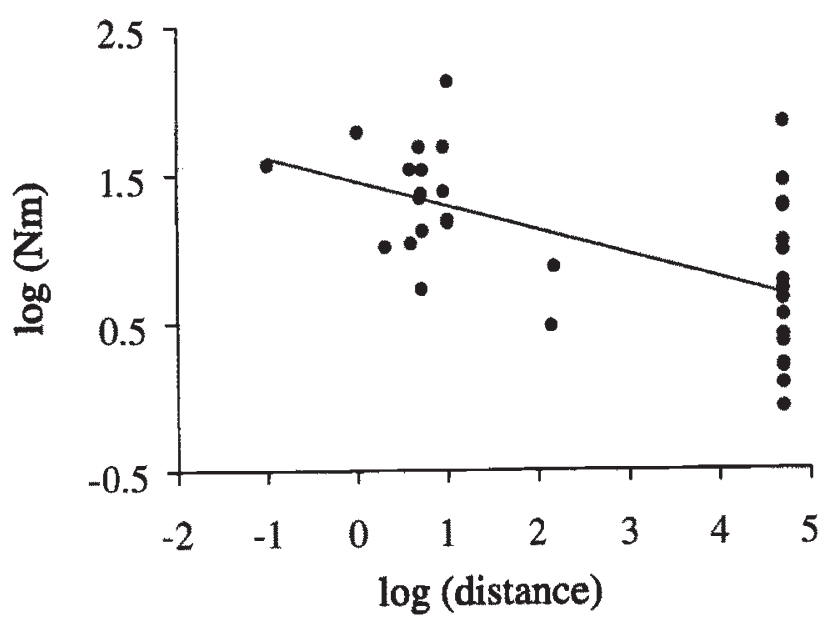

Fig. 2 Isolation by distance (in m) using Slatkin's (1993) method. Pairwise estimates of $\mathrm{Nm}$ were calculated using the $G_{\text {ST }}$ parameter of Nei $(1973)$ because some $F_{\text {ST }}$ estimates of Weir and Cockerham (1984) were negative. collected on the continent and in Crete was higher than between samples from Crete $\left(F_{\mathrm{ST}}=0.14\right.$, estimated after pooling samples of the two regions), indicating a very low gene flow $(\mathrm{Nm}=1.5)$.

\section{Discussion}

Our study showed that, in Crete, population structure of T. urticae is independent of the species of the host-plant colonized, but is affected by the density of mites on these plants as well by the distances that separate them.

The absence of significant differentiation among T. urticae colonizing different host-plants was well demonstrated by the study undertaken in Neo Chorio on mites collected on pumpkin, tomato, okra, weed plants and citrus trees. The $F_{\mathrm{ST}}$ estimate among samples was low $\left(F_{\mathrm{ST}}=0.01\right)$ and, consequently, gene flow very high $(\mathrm{Nm}=24)$. These results contrast with a recent report by Gotoh et al. (1993) who showed clear mating and host-plant preferences associated with the Pgi polymorphism in two strains of $T$. urticae from The Netherlands. These strains were established from mites coming from two different greenhouses and host plants (cucumbers and tomatoes) and had been reared for many years on their respective host plants. In addition to genetic drift, they had therefore experienced different selection pressures. This was not the case of the openfield populations considered in Neo Chorio.

The study carried out in Neo Chorio revealed also the importance of population density on spider mite population structure: samples collected from several plants carrying mites in low densities displayed significant heterozygote deficits whereas those collected on plants with high densities did not. This suggests that, at low densities, mites on different plants had slightly different allelic frequencies, probably as a result of founder effect and genetic drift. The importance of founder effect was evident by comparing successive leaves of a heavily parasitized pumpkin branch. The two older leaves of this branch carried T. urticae colonies which did not differ from one another or from the other Neo Chorio samples. Mites on the younger leaf were significantly different from all other samples and showed a low heterozygosity $\left(H_{\mathrm{o}}=0.04\right.$ compared to $0.11-0.29$ in other samples). Evidence of founder effect has been reported in $T$. urticae by Hinomoto \& Takafuji (1994) who studied the Pgi locus. These authors observed increased heterozygote deficits (measured by the inbreeding coefficient $F_{\text {IS }}$ ) as they considered successively mites collected on individual leaflets, individual plants, or all the strawberry plants present 
in a vinyl house. In a study of the $M d h$ locus, Ward et al. (1982) found that genotypic frequencies were in agreement with the Hardy-Weinberg expectations although their sampling covered many plants within a $600 \mathrm{~m}^{2}$ area, and we can conclude that founder effect was negligible. As noted by Hinomoto \& Takafuji (1994), the difference between the two studies may be caused by different densities. In addition, Ward et al. (1982) studied a single locus which may not have been representative of the real situation. In the present investigation, evidence of heterozygote deficits on plants carrying low densities of mites was not uniformly distributed among the four loci studied: it was not, for example, detectable at the Pgi locus. This emphasizes the advantage of multilocus analyses compared to single-locus analyses, which were the only ones possible until recently as a result of the lack of adequate electrophoretic techniques for very small organisms.

The strong differentiation observed between samples collected in different sites of the Armeni village indicated that a distance of $150 \mathrm{~m}$ was sufficient to considerably limit gene flow. Limitation of gene flow in relation to geographical distance was further confirmed by the significant correlation observed between differentiation (measured by $F_{\text {ST }}$ estimates) and distance when considering the whole data set. Similar results have been found by Osakabe \& Sakagami (1993) with the citrus mite Panonychus citri (McGregor) in Japan.

The dispersal behaviour of $T$. urticae has been the subject of extensive studies. This species tends to feed in colonies of relatives on the same host leaf (Mitchell, 1973) until environmental conditions deteriorate following exhaustion of food resources, increased densities of predatory mites or the repellent effects of pesticides (see Grafton-Cardwell et al., 1991). Two active dispersal behaviours have been reported: crawling and taking advantage of air draughts (Kennedy \& Smitley, 1985). Crawling ensures dispersal in two ways: (a) between adjacent plants and (b) on the same plant from older leaves to new ones, usually from the base to the top of the plant as density increases and older leaves become unsuitable (Hussey \& Parr, 1963). To colonize new plants, mites may let themselves be blown away or may drop to the soil, after hanging at the end of their silk line for some time (Fleschner et al., 1956). T. urticae manifests another particular behaviour during which mites orientate themselves away from the light source and raise their forelegs and forebodies (Smitley \& Kennedy, 1985). This behaviour occurs in the presence of air currents and increases the probability of being blown away; it is manifested especially by young mated females (Li \& Margolies, 1993). In a maize-peanut agroecosystem, ground crawling was observed in the spring when $T$. urticae moved from overwintering sites to adjacent maize fields, and aerial dispersal was observed for the subsequent colonization of peanut plants later in the season (Brandenburg \& Kennedy, 1982; Margolies \& Kennedy, 1985).

Our observations on the population structure of $T$. urticae in Crete agree well with the known pattern of dispersal of the species. Increased tendency of dispersal on plants with high densities of mites is likely to ensure panmixia and explains the absence of a heterozygote deficit in mites from heavily parasitized plants. Dispersal between adjacent plants will mostly be dependent on crawling, because once 'airborne' mites have a low probability of falling on a nearby plant. Dispersal by crawling can only maintain panmixia over short distances, even if a high proportion of the population is involved. This agrees well with our finding that samples at $150 \mathrm{~m}$ from one another are significantly differentiated, as well as with the significant correlation between $F_{\mathrm{ST}}$ estimates and geographical distances. Our results are also consistent with the large differentiation observed between samples collected in Crete and in continental Greece, two areas between which genetic exchanges are most probably associated with passive migration resulting from the transport of plants rather than active dispersal.

In conclusion, our study shows that, in Crete, $T$. urticae populations colonizing different host-plants largely interbreed in open-field environments over areas of some $50 \mathrm{~m}^{2}$ or less, at least when population densities are high, i.e. in conditions known to increase the number of individuals displaying dispersal behaviours. The disruption of panmixia, which leads to genetic differentiation (as a result of founder effect and genetic drift), is detectable between groups of plants separated by $150 \mathrm{~m}$, and is consistent with the known means of active dispersal in the species. Whether these conclusions are specific to T. urticae from the studied region or can be generalized to the whole species will have to be investigated.

\section{Acknowledgements}

We thank M. Raymond, F. Rousset, H. Thistlewood, J. Gutierrez and P. Souliotis for valuable suggestions, and M. Paraskakis for providing laboratory facilities at the Institute of Subtropical Plants and Olive Trees at Chania, Crete. A.T. is supported by a 
fellowship from the Bakala Foundation (Greece). This is contribution no. $96-055$ of the Institut des Sciences de l'Evolution.

\section{References}

BRANDENBURG, R. L. AND KENNEDY, G. G. 1982. Intercrop relationships and spider mite dispersal in a corn/peanut agro-ecosystem. Entomologia exp. appl., 32, 269-276.

DE BOER, R. 1985. Reproductive barriers. In: Helle, W. and Sabelis, M. W. (eds), Spider Mites: Their Biology, Natural Enemies and Control, vol. 1 A, pp. 193-199. Elsevier Science Publishers, Amsterdam.

DEMPSTER, A. P., LAIRD, N. M. AND RUBIN, D. B. 1977. Maximum likelihood from incomplete data via the EM algorithm. J. R. Statist. Soc. B, 39, 1-38.

FISHER, R. A. 1970. Statistical Methods for Research Workers, 14th edn. Olivier and Boyd, Edinburgh.

FLESCHNER, C. A., BADGLEY, M. E., RICKER, D. W. AND HALL, J. C. 1956. Air drift of spider mites. J. Econ. Entomol., 49, 624-627.

GARNIER-GERE, P. AND DILLMANN, C. 1992. A computer program for testing pairwise linkage disequilibria in subdivided populations. J. Hered., 83, 239.

GOTOH, T., BRUIN, J., SABELIS, M. W. AND MENKEN, S. B. J. 1993. Host race formation in Tetranychus urticae: genetic differentiation, host plant preference, and mate choice in a tomato and a cucumber strain. Entomologia exp. appl., 68, 171-178.

GRAFTON-CARDWELL, E. E., GRANETT, J. AND NORMINGTON, S. M. 1991. Influence of dispersal from almonds on the population dynamics and acaricide resistance frequencies of spider mites infesting neighboring cotton. Exp. Appl. Acarol., 10, 187-212.

HELLE, W. AND OVERMEER, W. P. J. 1973. Variability in tetranychid mites. Ann. Rev. Ent., 18, 97-120.

HinOMOTO, N. AND TAKafuji, A. 1994. Studies on the population structure of the two-spotted spider mite, Tetranychus urticae Koch, by allozyme variability analysis. Appl. Ent. Zool., 29, 259-266.

HOLM, s. 1979. A simple sequentially rejective multiple test procedure. Scand. J. Statist., 6, 65-70.

HUSSEY, N. W. AND PARR, W. J. 1963. Dispersal of the glasshouse red spider mite Tetranychus urticae Koch (Acarina, Tetranychidae). Entomologia exp. appl., 6, 207-214.

JONES, S. A. AND MORSE, J. G. 1995. Use of isoelectric focusing electrophoresis to evaluate citrus thrips (Thysanoptera: Thripidae) predation by Euseius tularensis (Acari: Phytoseiidae). Envir. Entomol., 24, 1040-1051.

KAZMER, D. J. 1991. Isoelectric focusing procedures for the analysis of allozymes variation in minute arthropods. Ann. Entomol. Soc. Am., 84, 332-339.

KENNEDY, G. G. AND SMITLEY, D. R. 1985. Dispersal. In: Helle, W. and Sabelis, M. W. (eds), Spider Mites: Their
Biology, Natural Enemies and Control, vol. 1 A, pp. 233-242. Elsevier Science Publishers, Amsterdam.

LEDUC, A., DRAPEAU, P., BERGERON, Y. AND LEGENDRE, P. 1992. Study of partial components of forest cover using partial Mantel tests and path analysis. J. Veget. Sci., 3, 69-78.

L1, J. AND MARGolies, D. C. 1993. Effects of age, mite density, and host quality on aerial dispersal behaviour in the two-spotted spider mite. Entomologia exp. appl., 68, 79-86.

MARGOLIES, D. C. AND KENNEDY, G. G. 1985. Movement of the twospotted spider mite, Tetranychus urticae, among hosts in a corn-peanut agroecosystem. Entomologia exp. appl., 37, 55-61.

MITCHELL, R. 1973. Growth and population dynamics of a spider mite (Tetranychus urticae, K., Acarina: Tetranychidae). Ecology, 54, 1349-1355.

NEI, M. 1973. Analysis of gene diversity in subdivided populations. Proc. Natl. Acad. Sci. U.S.A., 70, 3321-3323.

OHTA, T. 1982. Linkage disequilibrium due to random genetic drift in finite subdivided populations. Proc. Natl. Acad. Sci. U.S.A., 79, 1940-1944.

oSAKABE, M. AND SAKAGAMI, Y. 1993. Protein differences detected by two-dimensional electrophoresis among local populations of Panonychus citri (McGregor) (Acari: Tetranychidae) in Japan. Appl. Ent. Zool., 28, 497-502.

PASTEUR, N., PASTEUR, G., CATALAN, J., BONHOMME, F. AND Britton-DAVidian, J. 1988. Practical Isozyme Genetics. Ellis Horwood Ltd, Chichester, England.

RAYMOND, M. AND ROUSSET, F. 1995a. GENEPOP (Version 1.2): population genetics software for exact tests and ecumenicism. J. Hered., 86, 248-269.

RAYMOND, M. AND ROUSSET, F. 1995b. An exact test for population differentiation. Evolution, 49, 1280-1283.

ROUSSET, F. AND RAYMOND, M. 1995. Testing heterozygote excess and deficiency. Genetics, 140, 1413-1419.

SLATKIN, M. 1985. Rare alleles as indicators of gene flow. Evolution, 39, 53-65.

SLATKIN, M. 1993. Isolation by distance in equilibrium and non-equilibrium populations. Evolution, 47, 264-279.

SMITLEY, D. R. AND KENNEDY, G. G. 1985. Photo-orientated aerial-dispersal behaviour of Tetranychus urticae (Acari: Tetranychidae) enhances escape from the leaf surface. Ann. Entomol. Soc. Am., 78, 609-614.

SMOUSE, P. E., LONG, J. L. AND SOKAL, R. R. 1986. Multiple regression and correlation extensions of the Mantel test of matrix correspondence. Syst. Zool., 35, 627-632.

tSAGKarakou, A., Guillemaud, T., RousSeT, F. AND NAVAJAS, M. 1996a. Molecular identification of a Wolbachia endosymbiont in a Tetranychus urticae strain (Acari: Tetranychidae). Insect Mol. Biol., 5, 217-221.

TSAGKARAKOU, A., NAVAJAS, M., LAGNEL, J., GUTIERREZ, J. AND PASTEUR, N. 1996b. Genetic variability in Tetranychus urticae from Greece (Acari: Tetranychidae): insecticide resistance and isozymes. J. Econ. Entomol., 89 (in press). 
WARD, P. S., BOUSSY, I. A. AND SWINCER, D. E. 1982. Electrophoretic detection of enzyme polymorphism and differentiation in three species of spider mites (Tetranychus) (Acari: Tetranychidae). Ann. Entomol. Soc. Am., 75, 595-598.
WEIR, B. S. AND COCKERHAM, C. C. 1984 . Estimating $F$-statistics for the analysis of population structure. Evolution, 38, $1358-1370$.

WRIGHT, s. 1969. Evolution and the Genetics of Populations, vol. 2, The Theory of Gene Frequencies. Chicago University Press, Chicago. 